\title{
Inhibitory effects of retinoic acid and IIF on growth, migration and invasiveness in the U87MG human glioblastoma cell line
}

\author{
A. PAPI ${ }^{1}$, G. BARTOLINI ${ }^{1}$, K. AMMAR ${ }^{1}$, F. GUERRA $^{2}$, A.M. FERRERI $^{2}$, \\ P. ROCCHI ${ }^{2}$ and M. ORLANDI ${ }^{1}$ \\ ${ }^{1}$ Department of Experimental Evolutive Biology, University of Bologna, Bologna, via Selmi 3, 40126 Bologna; \\ ${ }^{2}$ Department of Experimental Pathology, University of Bologna, Bologna, viale Filopanti 22, 40126 Bologna, Italy
}

Received April 19, 2007; Accepted June 7, 2007

\begin{abstract}
Glioblastomas, the most malignant and prevalent brain tumors which remain incurable, are characterized by both extensive proliferation and invasive growth. We previously reported a remarkable antitumoral effect of the retinoid 6-OH-11-O-hydroxyphenantrene (IIF) on neuroblastoma, leukemia and colon carcinoma cells. In this study we examined the effect of IIF on proliferation, apoptosis and cell invasion in the human glioblastoma cell line U87MG, in comparison with all-trans-retinoic acid (RA). Our results showed that both retinoids induced cell growth inhibition and apoptosis in a dose- and time-dependent manner. We also demonstrated that the invasive ability of glioblastoma cells decreased after treatment with IIF or RA. Since cell invasion involves a complex system of tightly regulated proteases, matrix metalloproteinases (MMPs) and their specific inhibitors, tissue inhibitors of MMPs (TIMPs), we analysed the effect of IIF on MMP and TIMP expression in comparison with RA. Treatment with both retinoids resulted in a marked decrease of MMP2 and MMP9 expression and of lytic activity of MMP2. In addition, exposure to IIF led to enhanced expression of TIMP2. Collectively, our results demonstrated the effectiveness of both IIF and RA in inhibiting proliferation, cell migration, and the invasive potential of glioblastoma U87MG cells. Notably, the anticancer activity of IIF, on the whole, was more pronounced than that of RA. Therefore, these findings, besides providing further evidence that IIF may be a powerful tool in the development of cancer treatments, suggest that IIF may have therapeutic potential against the invasiveness of brain tumors.
\end{abstract}

Correspondence to: Professor Anna Maria Ferreri, Dipartimento di Patologia Sperimentale, Sezione Cancerologia, University of Bologna, viale Filopanti 22, 40126 Bologna, Italy

E-mail: ferreri@cancer.unibo.it

Key words: glioblastoma, IIF, invasion, retinoids, metalloproteinases

\section{Introduction}

Gliomas are the most prevalent primary brain tumors, accounting for $>50 \%$ of all brain tumors (1-2). Current treatment options include surgery, radiation therapy, and chemotherapy. Unfortunately, the prognosis of patients with glioblastomas remains extremely poor, and the median survival of 12 months from the time of diagnosis has not significantly changed during the last few years (3-4). New approaches are therefore essential for the treatment of these patients, especially because the occurrence of gliomas is increasing. Invasive behaviour is the pathological hallmark of malignant gliomas, being responsible for the failure of surgery, radiation and chemotherapy (5-6).

Cell invasion is a multistep cellular process in which a major role is played by the proteolysis of the extracellular matrix (ECM) components, such as collagen type IV and laminin by matrix metalloproteinases (MMPs). In particular, the expression and proteolytic activity of the so-called gelatinases, MMP2 and MMP9, are also well correlated with the progression and the degree of malignancy in gliomas (7-11).

The activity of MMPs is finely regulated by tissue metalloproteinase inhibitors (TIMPs); an imbalance between the production of MMPs and their inhibition by TIMPs, leading to excess degradation of the ECM, underlies the invasive potential of brain tumors (12-14). In particular, TIMP1 and TIMP2 regulate MMP9 and MMP2 respectively. Thus, inhibitors of MMPs could potentially be useful for blocking cancer progression.

Retinoids, a group of natural and synthetic analogs of vitamin A, play an important role in cell proliferation and differentiation (15). Because retinoid treatment inhibits the growth of a variety of epithelial cancers, retinoids have great promise in the area of cancer chemotherapy and chemoprevention (16-18). However, the use of these agents is significantly hampered by their toxicity and the emergence of resistance $(19,20)$. Hence major efforts are underway to detect new retinoids which could exhibit similar anticancer activities but with reduced toxicity in vivo. The retinoid signal is mediated through specific nuclear receptors: the retinoic acid receptor (RAR) and the retinoid X receptor (RXR). It has been demonstrated that retinoids which are specific ligands of RXR are effective as antitumoral agents as RAR 
ligands, and are devoid of side effects (21). Therefore, many retinoids able to bind RXR with high affinity have been synthesized, among which is the derivative of the all-transretinoic acid (RA), 6-OH-11-O-hydroxyphenantrene (IIF) (22). In previous studies we demonstrated that this compound had a strong antitumoral effect on neuroblastoma, leukemia and colon carcinoma cells (22-25).

In this study we investigated the anticancer properties of IIF in the human glioblastoma cell line U87MG, in comparison with the primary biologically active retinoid RA by analyzing the effect of both retinoids on cell proliferation, on the induction of apoptosis and on the expression of genes and proteins involved in the mechanism leading to tumor invasion.

\section{Materials and methods}

Cell culture. The human tumor cell line U87MG, obtained from Interlab Cell Line Collections (Genoa, Italy), was maintained in RPMI (Sigma, St. Louis, MO, USA) supplemented with $10 \%$ fetal bovine serum (FBS), $2 \mathrm{mM}$ glutamine, $50 \mathrm{U} / \mathrm{ml}$ penicillin and $50 \mu \mathrm{g} / \mathrm{ml}$ streptomycin and grown at $37^{\circ} \mathrm{C}$ in humidified air with $5 \% \mathrm{CO}_{2}$.

IIF (pat. WIPO W0 00/17143, Bologna, Italy) and RA (Sigma) were dissolved in propylene glycol and ethanol respectively, just before use, and the final concentrations in the range 10-40 $\mu \mathrm{M}$ were obtained with the culture medium. The concentration of the solvent in the highest dose of drugs did not affect cell proliferation and invasion of the cell lines.

MTT assay. The effect of IIF and RA on cell viability was evaluated by MTT [3-(4,5-dimethylthiazol-2-yl)-2,5diphenyltetrazolium bromide] assay (26), based on the reduction of the number of metabolically active cells, and the results were expressed as a percentage of the controls. Briefly, $3 \times 10^{3}$ cells/well were seeded into a 96-well plate and treated with specific concentrations of IIF or RA for 3, 6, or 10 days, after which $0.5 \mathrm{mg} / \mathrm{ml}$ of MTT (Sigma) was added to each well and incubated for $4 \mathrm{~h}$ at $37^{\circ} \mathrm{C}$. Following the incubation, a solution containing $10 \% \mathrm{SDS}$ and $0.01 \mathrm{M} \mathrm{HCl}$ was added. After a minimum of $18 \mathrm{~h}$ at $37^{\circ} \mathrm{C}$, the absorbance of each well was measured in a microplate reader (Bio-Rad, Hercules, CA, USA) at $570 \mathrm{~nm}$. The results were expressed as a percentage of the controls.

Annexin V apoptosis detection assay. Experiments were performed on cells seeded in 6-well plates at a density of $8 \times 10^{4}$ cells/well treated for one day with IIF and RA $(20 \mu \mathrm{M})$ (27). Samples were prepared using $0.5 \mu \mathrm{g}$ of Annexin VFITC per slide (Bender MedSystems, Austria) for $15 \mathrm{~min}$ in the dark. After incubation, the cells were fixed with paraformaldehyde at $4^{\circ} \mathrm{C}$ for $30 \mathrm{~min}$ and marked with $10 \mu \mathrm{l}$ of $1 \mu \mathrm{g} / \mathrm{ml}$ propidium iodide per $100 \mu 1$ assay buffer. After washing with phosphate-buffered saline (PBS) and water, samples were observed under a fluorescence microscope using a dual filter set for FITC and rhodamine.

MMP activity. The MMP2 activity of the U87MG cells was determined by gelatin zimography (28). After a 4-day treatment with RA (10-20 $\mu \mathrm{M})$ or IIF (10-20 $\mu \mathrm{M})$, the cells were washed with PBS and replaced in serum-free medium
(RPMI) for $18 \mathrm{~h}$ with the same treatment. After centrifugation ( $300 \mathrm{x}$ g for $10 \mathrm{~min}$ ) the supernatant was separated and the protein concentration was determinated; $10 \mu \mathrm{g}$ per lane added to sample buffer [1 $\mathrm{M}$ Tris- $\mathrm{HCl}, \mathrm{pH} 6.8,2 \%$ sodium dodecyl sulphate (SDS), and $10 \%$ glycerol] was applied to $10 \%$ SDS-polyacrylamide gel containing $1 \mathrm{mg} / \mathrm{ml}$ gelatin (Sigma). After electrophoresis, SDS was removed from the gel by washing twice with $2.5 \%$ Triton X-100 for $1 \mathrm{~h}$. After a brief rinse, the gel was incubated at $37^{\circ} \mathrm{C}$ for $18 \mathrm{~h}$ in buffer, pH 7.6, containing $100 \mathrm{mM}$ Tris- $\mathrm{HCl}, 10 \mathrm{mM} \mathrm{CaCl}_{2}$, and $20 \mathrm{mM} \mathrm{NaCl}$. The gel was stained with $1 \%$ Coomassie Brillant Blue R250 for $2 \mathrm{~h}$ and then destained with destaining solution (40\% methanol, $10 \%$ acetic acid, and 50\% distilled water). The MMP2 activity was discernible by clear bands of gelatin digestion on a blue background. The activity of MMP2 in the gel was quantified by using a densitometric image analysis software (Image Master VDS, Pharmacia Biotech, Uppsala, Sweden). No MMP9 activity was exhibited in the gel under these experimental conditions.

Western blot analysis. To determine MMP2, MMP9, TIMP1, TIMP2 and Bc12 levels, U87MG cells were plated and treated with retinoids as described above for zimography. The cells were detached and were collected by centrifugation at $300 \mathrm{x} \mathrm{g}$ for $10 \mathrm{~min}$, and the pellets were re-suspended in lysis buffer (20 mM Tris- $\mathrm{HCl}, \mathrm{pH} 7.5,0.5 \mathrm{mM}$ EDTA, 0.5\% Triton $\mathrm{X}$ 100 , and $5 \mu \mathrm{M} \mathrm{Na}_{3} \mathrm{VO}_{4}$ ) and sonicated on ice in the presence of protease inhibitors. The protein concentration was determined by the method of Lowry (29). Cell lysates (50 $\mu \mathrm{g}$ of protein per lane) were size-fractioned in 10\% SDS-polyacrylamide gel prior to transfer to Hybond ${ }^{\mathrm{TM}}-\mathrm{C}$ Extra membranes (GE Healthcare, Milan, Italy) according to standard protocol. Membranes were blocked for $2 \mathrm{~h}$ with 5\% milk in transfer buffer saline (TBS) at RT. The membranes were incubated overnight at $4{ }^{\circ} \mathrm{C}$ with anti-MMP2, antiMMP9, anti-TIMP1, anti-TIMP2, or anti-Bcl2 dissolved in TBS-5\% milk. All the antibodies employed were from Santa Cruz Biotechnology, Santa Cruz, CA, USA. The membranes were washed two times with TBS-5\% milk and were incubated for $1 \mathrm{~h}$ with the respective peroxidase-conjugated antibodies. The anti-MMP2 and the anti-MMP9 were diluted 1:700; the anti-TIMP1 and the anti-TIMP2, 1:400; the anti-Bcl2, 1:300; and the anti-rabbit peroxidase-conjugated antibodies were diluted 1:1000, respectively with 5\% milk in TBS-1\% Tween. The proteins were detected by luminol (GE Healthcare). Bands were quantified by using a densitometric image analysis software (Image Master VDS). The amount of protein in each lane was equal, as confirmed by actin.

Real-time polymerase chain reaction. Real-time PCR was used for relative quantification of MMP2 and MMP9 gene expression in U87MG cancer cells. Total RNA was isolated using Eurozol (Euroclone, Milan, Italy) and re-suspended in RNAse-free water. Gel electrophoresis confirmed the quality of the isolated total RNA from each sample, and $1.0 \mu \mathrm{g}$ of RNA was reverse transcribed in cDNA for real-time PCR.

The primer sequences which were used included: MMP2 forward, 5'-CTGAAGGACACACTAAAGAAGATG-3' (Tm, 55.2 ${ }^{\circ} \mathrm{C}$ ); MMP2 reverse, 5'-GGAAACGAGCACGGAAGG$3^{\prime}\left(\mathrm{Tm}, 55.2^{\circ} \mathrm{C}\right)$; MMP9 forward, 5'-CGACGATGACGAC 
A

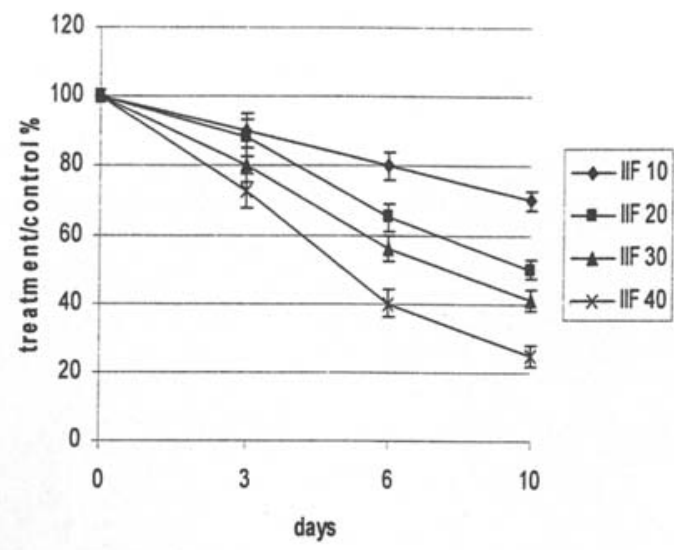

B

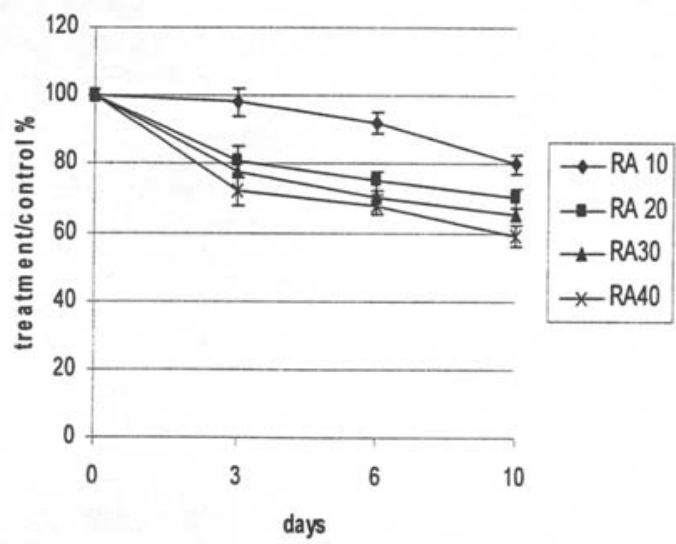

Figure 1. Effect of different doses $(\mu \mathrm{M})$ of IIF (A) and RA (B) on U87MG cell growth as assessed by MTT assay. Each bar represents the mean $\pm \mathrm{SE}$ of six replicate cultures from three independent experiments.

GAGTTGTGG-3' (Tm, 55.5 $\left.{ }^{\circ} \mathrm{C}\right)$; MMP9 reverse, 5'-GGTGA AGGGGAAGTAGAAGC-3' (Tm, 55 $\mathrm{C})$; GUSB forward, 5'TGGTATAAGAAGTATCAGAAGCC-3' (Tm, 53 $\left.{ }^{\circ} \mathrm{C}\right)$; and GUSB reverse, 5'-GTATCTCTCTCGCAAAAGGAAC-3' $\left(\mathrm{Tm}, 54.4^{\circ} \mathrm{C}\right)$.

MMP2 and MMP9 mRNA levels for each sample were normalised against $\beta$-glucuronidase (GUSB) mRNA levels, and relative expression was calculated by using $C_{t}$ values. Real-time PCR was performed by using SYBR-Green Supermix and the IQ Cycler thermocycler (Bio-Rad).

Invasion assay. The invasion of cells into Matrigel was determined using Boyden chambers (NTG, Milan, Italy) with an $8.0-\mu \mathrm{m}$ pore size polycarbonate membrane (NTG, Milan, Italy) (30). The filter was coated with $12.5 \mu \mathrm{g}$ of Matrigel (Sigma). After $2 \mathrm{~h}, \mathrm{U} 87 \mathrm{MG}$ cells, treated or not with $20 \mu \mathrm{M}$ RA or $20 \mu \mathrm{M}$ IIF for 4 days, were seeded into the upper part of each chamber $\left(4 \times 10^{5}\right.$ cells/well in $800 \mu 1$ serum-free RPMI) with the same treatment. In the lower part of the chamber, $200 \mu 1$ chemoattractant (RPMI with $10 \%$ FBS) was added. After incubation for $18 \mathrm{~h}$ at $37^{\circ} \mathrm{C}$, non-migratory cells on the upper surface of the filter were wiped with a cotton swab, and the cells which migrated to the lower surface of

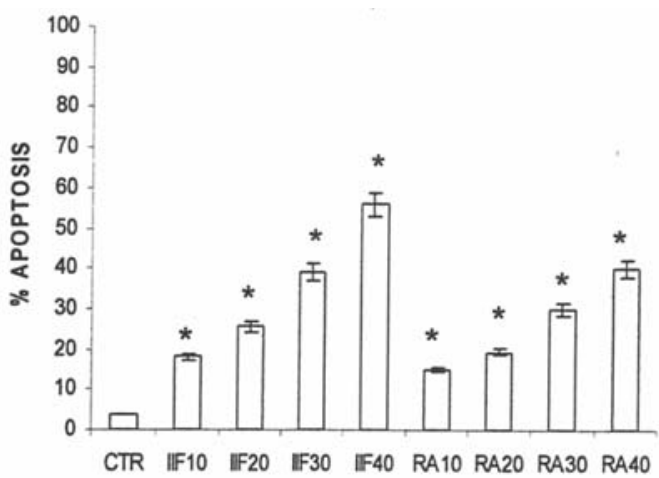

Figure 2. The induction of apoptosis by $10-40 \mu \mathrm{M}$ IIF and $10-40 \mu \mathrm{M}$ RA in U87MG cells after a 24-h exposure as assessed by Annexin V apoptosis assay. Apoptosis was evaluated by counting FITC-labeled cells in a minimum of five random fields and expressed as the percentage of total cells. CTR, untreated cells. Each bar represents the mean \pm SE of four experiments performed in duplicate; ${ }^{*} \mathrm{p}<0.05$.

the filter were fixed and stained with Toluidine blue. The invasive activity was evaluated by counting cells in five random fields using microscopy at x100 magnification.

Statistical analysis. Data were expressed as the mean \pm SE. Differences were analysed by the Student's t-test and considered statistically significant at $\mathrm{p}<0.05$ between the control and experimental samples.

\section{Results}

The effects of IIF and RA on U87MG cell growth, measured by MTT assay, are shown in Fig. 1. Both retinoids reduced cell proliferation, in a dose- and time-dependent manner. IIF exhibited a higher growth inhibitory effect than RA at equimolar doses.

Growth inhibition was accompanied by changes indicating that cells underwent apoptosis. Apoptotic cells were detected by the Annexin V test. FITC-labeled Annexin V binds the newly exposed phosphatidylserine (PS) at the outer membrane leaflet. In untreated samples, the amount of apoptotic cells was $3 \%$. Treatment with $40 \mu \mathrm{M}$ IIF or RA increased this percentage respectively to 56 and $40 \%$ (Fig. 2).

$\mathrm{Bcl} 2$ overexpression has been demonstrated in many cancer cells where its downregulation is indicative of apoptosis. We therefore evaluated the effect of IIF and RA on $\mathrm{Bcl} 2$ protein expression (Fig. 3). As demonstrated by Western blot analysis, both retinoids caused a dose-dependent downregulation of the $\mathrm{Bcl} 2$ protein, IIF being more effective than RA.

Invasion Matrigel assay was performed in order to determine the ability of retinoids to inhibit tissue invasion (Fig. 4). Our results showed that treatment with retinoids was followed by a decrease in the invasive activity of U87MG cells; $20 \mu \mathrm{M}$ IIF caused a $49 \%$ reduction in the migrating cells with respect to the controls, while a $41 \%$ reduction was obtained using RA at the same dose. A dose of $20 \mu \mathrm{M}$ was chosen in order to avoid possible misinterpretation of the results due to massive cell death occurring when higher doses of retinoids are used. 

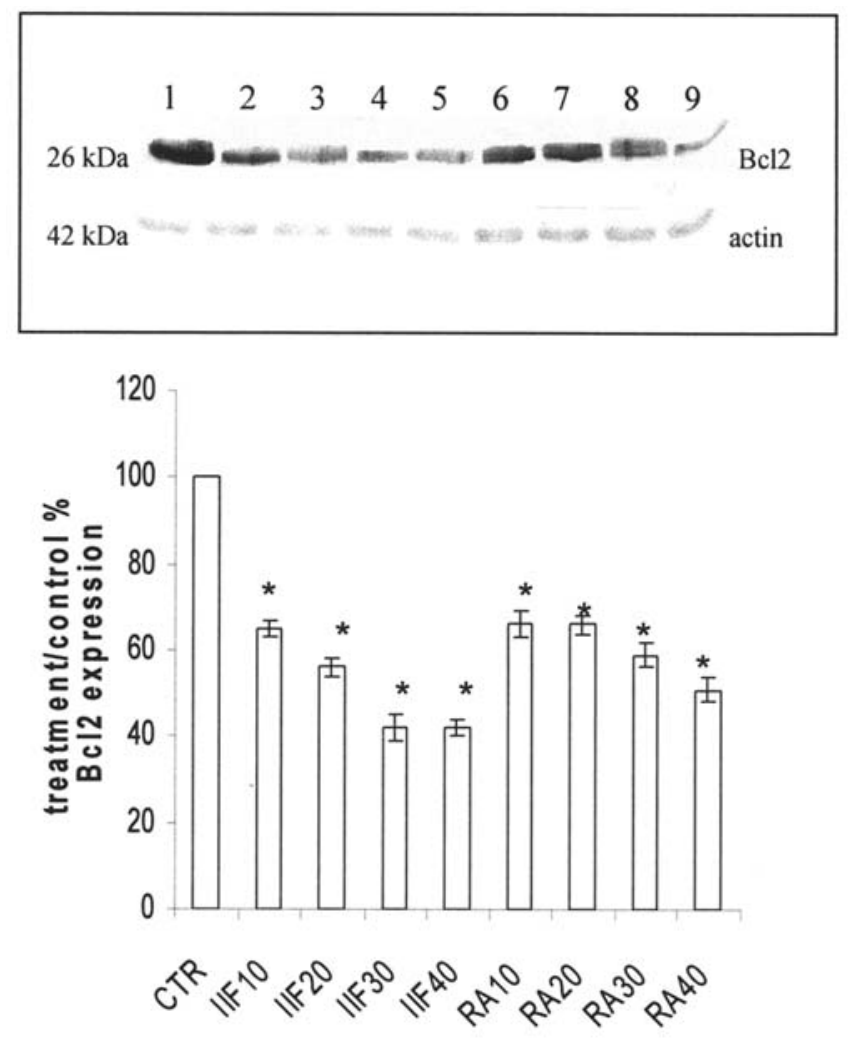

Figure 3. Western blot analysis for the Bcl2 protein level (top) in U87MG cells after a 5-day exposure to 10,20,30, and $40 \mu \mathrm{M} \mathrm{IIF}$ (number 2, 3, 4 and 5 , respectively) or $10,20,30$, and $40 \mu \mathrm{M} \mathrm{RA}$ (number $6,7,8$ and 9 , respectively). 1, control (CTR). Densitometric data are expressed as the percentage of treated samples with respect to CTR. Each bar represents the mean \pm SE of three independent experiments; ${ }^{*} \mathrm{p}<0.05$.

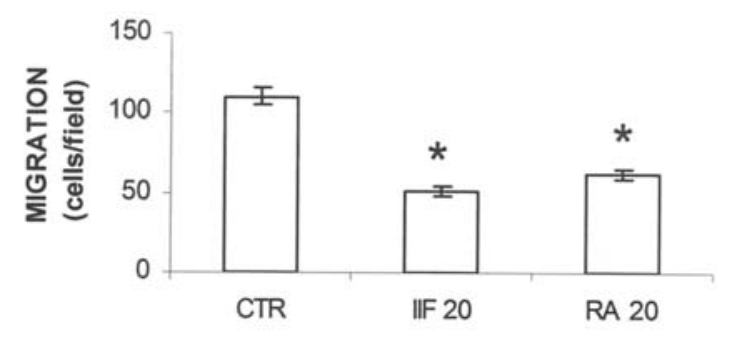

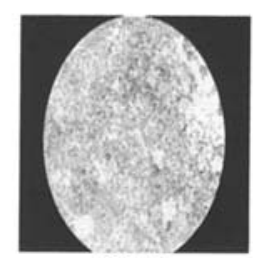

CTR

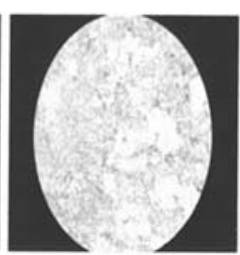

IIF 20

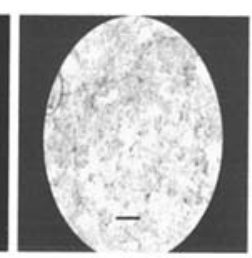

RA 20
Figure 4. Effect of RA and IIF $(20 \mu \mathrm{M})$ on invasion of U87MG cells as assessed by Matrigel invasion assay. Cells which migrated through the Matrigel-coated membranes were fixed, stained, photographed (bottom) and counted under light microscopy (top). Each bar represents the mean \pm SEM of three independent experiments. Bar, $100 \mu \mathrm{m} ;{ }^{*} \mathrm{p}<0.05$. CTR, control.

Since MMPs play a major role in tumor cell invasion, and MMP2 and MMP9 were shown to be upregulated in gliomas, we evaluated the effect of IIF and RA on their expression. As
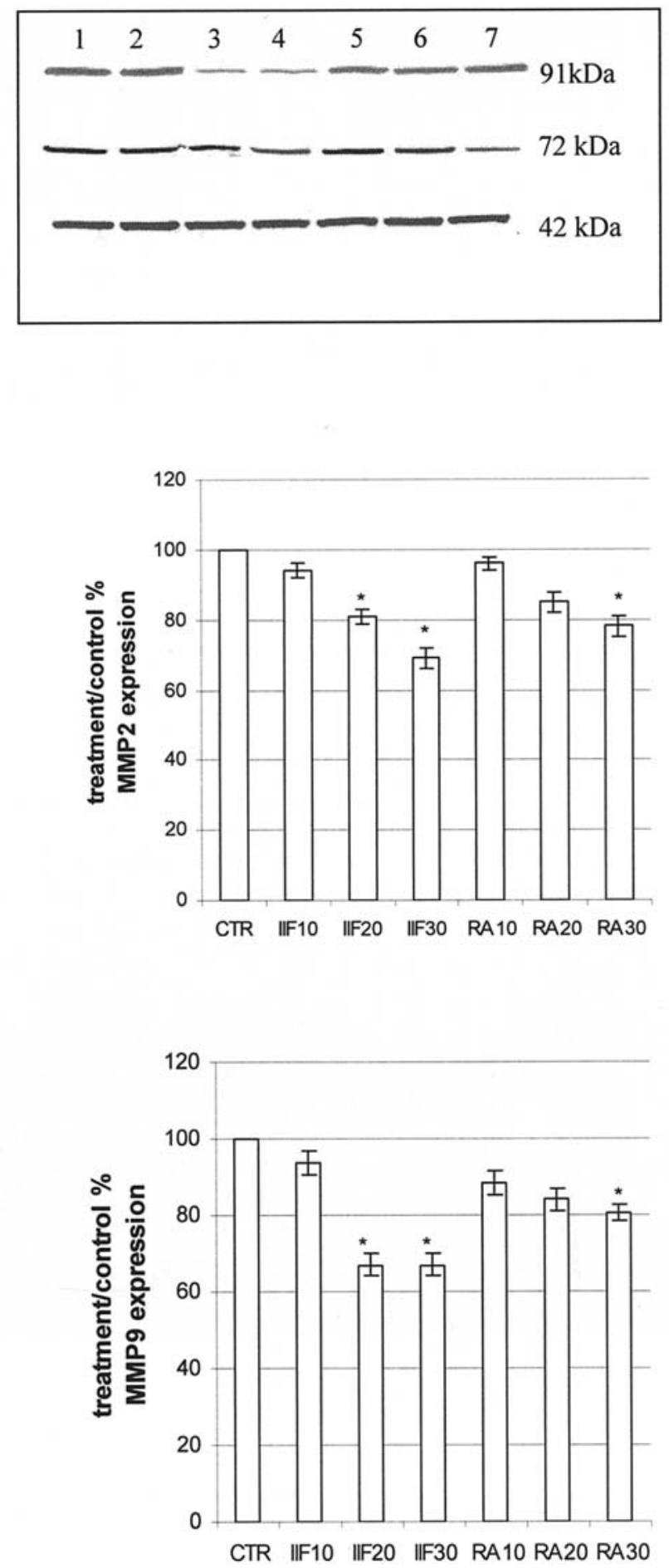

Figure 5. (Top) Effect of IIF and RA on MMP2 and MMP9 protein levels as assessed by Western blotting in cell lysates. U87MG cells were treated with 10,20 , and $30 \mu \mathrm{M} \mathrm{IIF} \mathrm{(number} \mathrm{2,} \mathrm{3,} \mathrm{and} \mathrm{4,} \mathrm{respectively)} \mathrm{or} \mathrm{10,} \mathrm{20,} 30 \mu \mathrm{M}$ RA (number 5, 6, and 7, respectively) for 5 days. 1, control (CTR). (Bottom) Densitometric data are expressed as the percentage of treated samples with respect to CTR. Each bar represents the mean \pm SE of three independent experiments; ${ }^{\mathrm{p}}<0.05$.

demonstrated by Western blot assay (Fig. 5), MMP2 and MMP9 expression levels were reduced by $30 \%$ with respect to the control when $30 \mu \mathrm{M}$ IIF was employed and $20 \%$ after treatment with RA at the same dose.

This result was confirmed by real-time PCR; both retinoids induced inhibition of MMP mRNA levels. As shown in Fig. 6, $20 \mu \mathrm{M}$ IIF induced a $42 \%$ decrease in MMP2 mRNA and a 


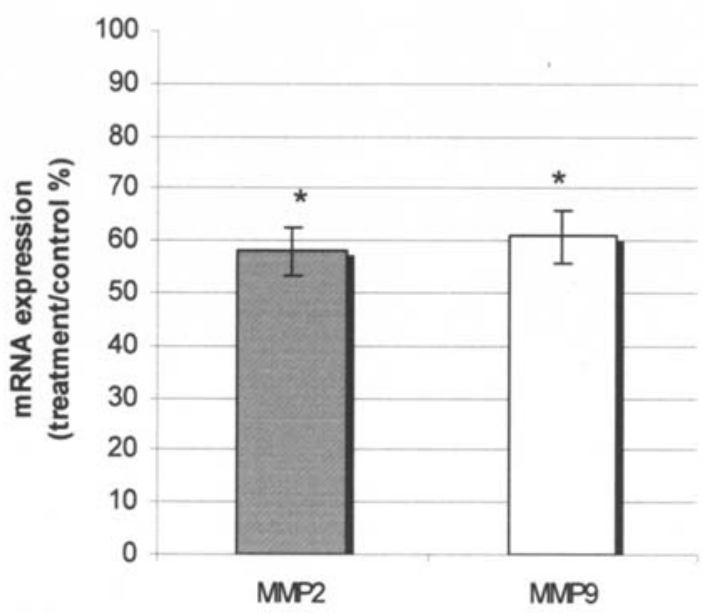

Figure 6. MMP2 and MMP9 mRNA expression in U87MG cells after a 5day exposure to $20 \mu \mathrm{M}$ IIF. Quantitative real-timePCR reactions were performed in duplicate, and each experiment was performed twice. Results $\pm \mathrm{SE}$ are expressed as the percentage of control; ${ }^{*} \mathrm{p}<0.05$.
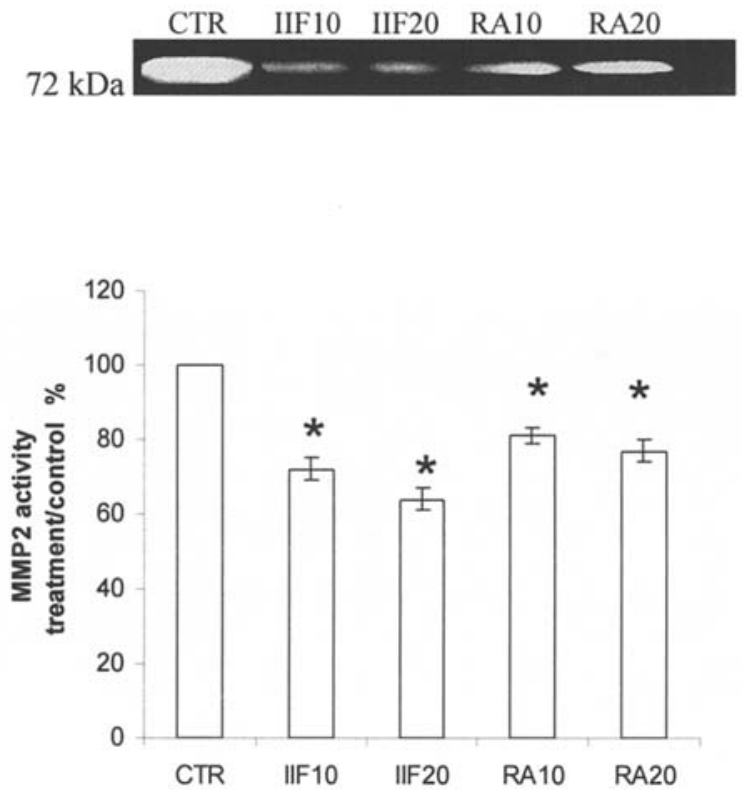

Figure 7. U87MG cells were treated with 0 (CTR), 10 or $20 \mu \mathrm{M} \mathrm{IIF}$ and RA for 5 days. Gelatin zymogram (top) showed the proMMP2 (72-kDa) form in serum-free conditioned media. Densitometric data (bottom) are expressed as the percentage of treated samples with respect to CTR. Each bar represents the mean $\pm \mathrm{SE}$ of three independent experiments; ${ }^{\mathrm{p}} \mathrm{p}<0.05$.

$39 \%$ decrease in MMP9 mRNA. After treatment with RA at the same dose, MMP2 and MMP9 mRNA was reduced by $20 \%$ (not shown).

We also examined the effect of IIF and RA on MMP2 enzymatic activity. As measured by gelatin zimography, a decrease in gelatinolytic activity of MMP2 was observed after exposure to IIF or RA, IIF being more effective than RA (Fig. 7).

Finally, in order to determine whether the exerted effect of IIF and RA on MMPs was accompanied by an effect on TIMPs, we analysed TIMP1 and TIMP 2 expression levels by Western blotting. Notably, as shown in Fig. 8, treatment with
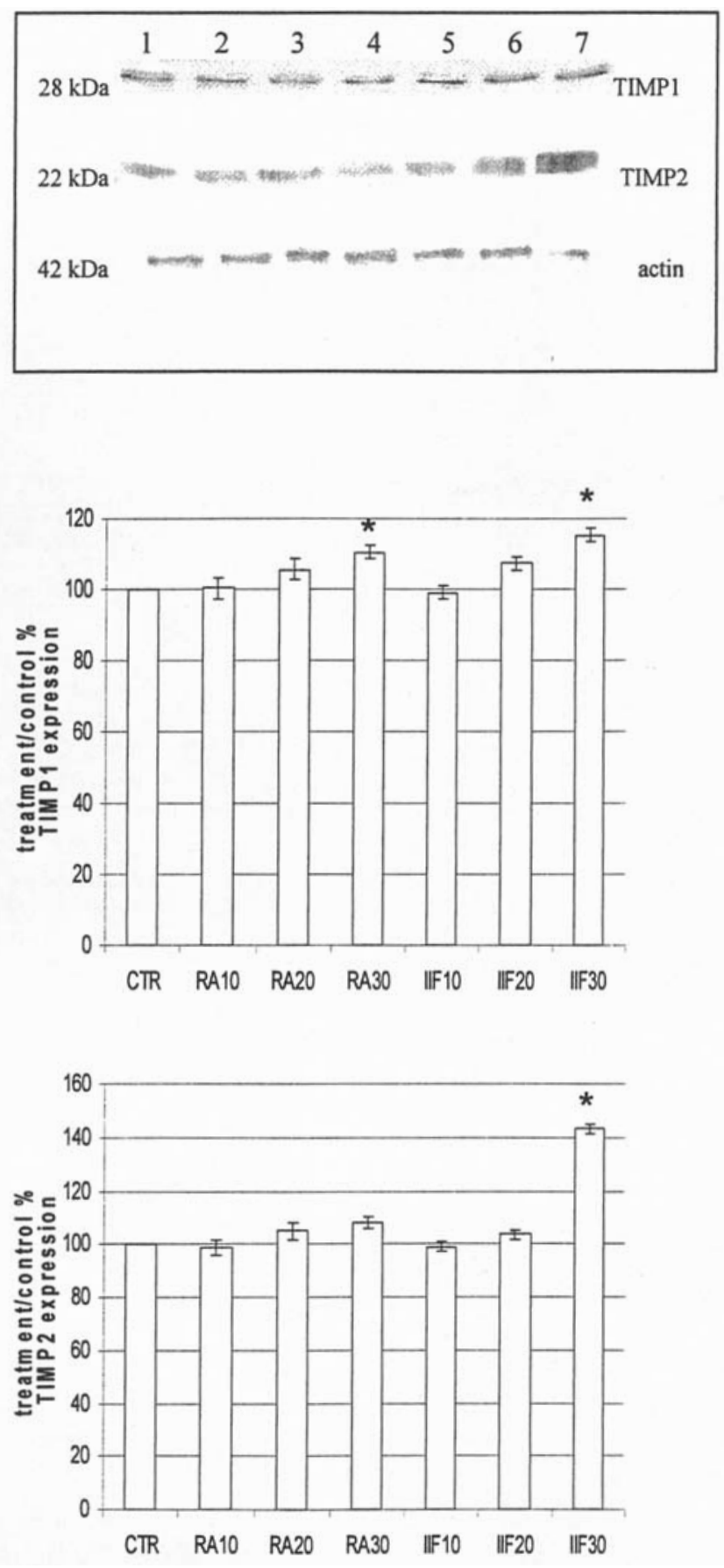

Figure 8. TIMP1 and TIMP2 protein levels as assessed by Western blotting (top), in U87MG cells after a 5-day exposure to 10,20 , and $30 \mu \mathrm{M}$ RA (number 2, 3 and 4, respectively) or 10, 20 and $30 \mu \mathrm{M} \mathrm{IIF} \mathrm{(number} \mathrm{5,} 6$ and 7, respectively); 1, control (CTR). Densitometric data (bottom) are expressed as the percentage of treated samples with respect to CTR. Each bar represents the mean $\pm \mathrm{SE}$ of three independent experiments; ${ }^{*} \mathrm{p}<0.05$.

$30 \mu \mathrm{M}$ IIF resulted in a $40 \%$ increase of TIMP2 and a $15 \%$ increase of TIMP1 protein level, while treatment with the same dose of RA significantly increased only TIMP1 expression.

\section{Discussion}

Retinoids have long been investigated in preclinical models, and clinical data have already supported the potential of these 
compounds as cancer preventive and therapeutic agents (15-18). In previous studies we demonstrated the strong antitumor activity of the retinoid IIF on many cancer cell lines, and its activity was consistently stronger than that exerted by RA (22-25).

The objective of the present research was to assess the potential of IIF as an anticancer agent on U87MG glioblastoma cells in comparison with RA.

The above reported data demonstrated that IIF had a strong antiproliferative effect, always higher than that exerted by RA. This effect was accompanied by a proapoptotic action. During apoptosis, the loss of phospholipid asymmetry occurs, which results in exposure of phosphatidylserine (PS) residues at the outer plasma membrane, which may serve as a trigger for phagocytosis (31). The exposure of PS has been demonstrated to occur early during the effector phase of apoptosis, probably downstream of changes in the mitochondria, and precedes the loss of plasma membrane integrity and DNA fragmentation (32). Treatment with RA and IIF induced a PS exposure, still detectable after $24 \mathrm{~h}$ as demonstrated by the Annexin $\mathrm{V}$ test.

Overexpression of the antiapoptotic protein $\mathrm{Bcl} 2$, reported in a wide variety of cancer cells, is associated with a diminished apoptotic response and resistance to various antitumor agents $(33,34)$. Bcl2 blocks apoptosis by inhibiting the release of mitochondrial proteins and PS exposure (32). Our results indicated that IIF and RA caused a downregulation of $\mathrm{Bcl} 2$ protein in U87MG cells.

This observation is particularly important because it was demonstrated that $\mathrm{Bcl} 2$ also promotes migration and invasiveness in human glioma cells (35). Invasive behaviour is the pathological hallmark of malignant gliomas and consequently the invasive cascade is an important therapeutic target. Invasion of tumor cells into normal tissue involves the interaction of tumor cells with ECM and surrounding cells, and their ability to secrete matrix-degrading proteases. Several models have been used to study invasive behaviour, the most widely used being the Matrigel invasion assay. By using this assay, we found a dose-dependent decrease in glioblastoma cell invasion by both retinoids, confirming the ability of retinoids to inhibit the invasive capacity $(36,37)$.

MMPs are thought to play a critical role in the invasive behaviour of glioblastoma. Particularly, MMP2 and MMP9 were found upregulated and also were associated with the degree of malignancy of gliomas (38-40), suggesting that these enzymes could be a molecular target in the treatment of glioma. In light of this, we investigated the effect of IIF, in comparison with RA, on MMP2 and MMP9 by Western blot, real-time PCR and gelatin zimography analyses. We found that retinoids inhibited MMP2 and MMP9 expression at both the mRNA and protein level, suggesting that the above reported inhibitory effect of retinoids on cell invasion could be due, at least in part, to the downregulation of MMP2 and MMP9 expression.

Furthermore, both retinoids dramatically reduced the enzymatic activity of MMP2. In our experimental conditions we were able to detect only negligible amounts of MMP9 gelatinolytic activity. Comparatively, in gliomas, MMP2 activity is very high with respect to that of MMP9 (41).
The catalytic activity of MMPs is closely regulated by their specific inhibitors, TIMPs. Changes in TIMP levels directly affect MMP activity since they have the ability to form tight 1:1 complexes with the active MMP enzymes (42-45). Therefore, in the present study, we investigated whether IIF and RA also affected the expression of TIMP1 and TIMP2, endogenous regulators of MMP9 and MMP2 respectively. Notably, we found that exposure to both retinoids, especially IIF, resulted in upregulation of TIMP2 expression.

The ability of glioma cells to infiltrate the surrounding brain tissue and escape current therapeutic modalities could potentially be minimized using anti-invasive therapies (46). Collectively, our results demonstrate the effectiveness of the retinoids IIF and RA as anticancer agents in glioblastoma U87MG cells. Remarkably, IIF exhibited heightened effectiveness over RA, in that it exerted major effects on growth, apoptosis, migration and invasive potential. It has been demonstrated that retinoids which are specific ligands of RXR are effective as antitumoral agents as RAR ligands, and are devoid of side effects (21). Our findings suggest that IIF, a ligand of RXR (22), may have good therapeutic potential in the treatment of brain tumors.

\section{Acknowledgements}

This study was supported by a grant from MURST, Italy. We thank Dr A. Strillaci for his support with the real-time PCR assay and Dr A. Santon for his support with the Annexin-V assay.

\section{References}

1. Kleihues P, Louis DN, Scheithauer BW, Rorke LB, Reifenberger G, Burger PC and Cavenee WK: The WHO classification of tumors of the nervous system. J Neuropathol Exp Neurol 61: 215-225, 2002.

2. Sanson M, Thillet J and Hoang-Xuan K: Molecular changes in gliomas. Curr Opin Oncol 16: 607-613, 2004.

3. Desjardins A, Rich JN, Quinn JA, Vredenburgh J, Gururang S, Sathornsumetee S, Reardon DA, Friedman AH, Bigner DD and Friedman HS: Chemotherapy and novel therapeutic approaches in malignant glioma. Front Biosci 10: 2645-2668, 2005.

4. Prados MD and Levin V: Biology and treatment of malignant glioma. Semin Oncol 27: 1-10, 2000.

5. Giese A, Bjerkvig R, Berens ME and Westphal M: Cost of migration: invasion of malignant gliomas and implications for treatment. J Clin Oncol 21: 1624-1636, 2003.

6. Rasheed BK, Wiltshire RN, Bigner SH and Bigner DD: Molecular pathogenesis of malignant gliomas. Curr Opin Oncol 11: 162-167, 1999.

7. Rooprai HK and McCormick D: Proteases and their inhibitors in human brain tumors: a review. Anticancer Res 17: 4151-4162, 1997.

8. Vince GH, Wagner S, Pietsch T, Klein R, Goldbrunner RH, Roseen $\mathrm{K}$ and Tonn JC: Heterogeneous regional expression patterns of matrix metalloproteinases in human malignant gliomas. Int J Dev Neurosci 17: 437-445, 1999.

9. Forsyth PA, Wong H, Laing TD, Rewcastle NB, Morris DG, Muzik H, Leco KJ, Johnston RN, Brasher PM, Sutherland G and Edwards DR: Gelatinase-A MMP2, gelatinase-B MMP-9 and membrane type matrix metalloproteinase-1 MT1-MMP are involved in different aspects of the pathophysiology of malignant gliomas. Br J Cancer 79: 1828-1835, 1999.

10. Stetler-Stevenson WG and Yu AE: Proteases in invasion: matrix metalloproteinases. Cancer Biol 11: 143-152, 2001.

11. Wang M, Wang GT, Liu S, Yoshida D and Teramoto A: The expression of matrix metalloproteinase-2 and -9 in human gliomas of different pathological grades. Brain Tumor Pathol 20: $65-72,2003$. 
12. Groft LL, Muzik H, Rewcastle NB, Johnston RN, Knauper V, Lafleur MA, Forsyth PA and Edwards DR: Differential expression and localization of TIMP-1 and TIMP-2 in human gliomas. Br J Cancer 85: 55-63, 2001.

13. Nakada M, Kita D, Futami K, Yamashita J, Fujimoto N, Sato H and Okada Y: Roles of membrane type 1 matrix metalloproteinase and tissue inhibitor of metalloproteinases 2 in invasion and dissemination of human malignant glioma. J Neurosurg 94: 464-473, 2001.

14. Correa TC, Brohem CA and Winnischofer SM: Downregulation of the RECK-tumor and metastasis suppressor gene in glioma invasiveness. J Cell Biochem 99: 156-167, 2006.

15. Kagechica H and Shudo K: Synthetic retinoids: recent development concerning structure and clinical utility. J Med Chem 48: 5875-5883, 2005

16. Sun SY and Lotan R: Retinoids and their receptors in cancer development and chemoprevention. Crit Rev Oncol Hematol 41: 41-55, 2002.

17. Jimenez-Lara AM, Clarke N, Altucci L and Gronemeyer $\mathrm{H}$ : Retinoic acid induced apoptosis in leukemia cells. Mol Med 10: 508-515, 2004.

18. Altucci L, Rosin A, Hirsch O, et al: Rexinoid-triggered differentiation and tumor selective apoptosis of acute myeloid leukemia by protein kinase A mediated desubordination of retinoid X receptor. Cancer Res 65: 8754-8765, 2005.

19. Petty WJ, Li N, Biddle A, Bounds R, Nitkin C, Ma Y, Dragnev KH, Freemantle SJ and Dmitrovsky E: A novel retinoic acid receptor beta isoform and retinoid resistance in lung carcinogenesis. J Natl Cancer Inst 97: 1645-1651, 2005.

20. Villabianca JG, Krailo MD, Ames MM, Reid JM, Reaman GH and Reynolds PC: Phase I trial of oral fenretinide in children with high-risk solid tumors: a report from the Children's Oncology Group (CCG 09709). J Clin Oncol 24: 3423-3430, 2006.

21. Kong G, Kim HT, Wu K, DeNardo D, Hilsenbeck SG, Xu XC, Lamph WW, Bissonnette R, Dannenberg AJ and Brown PH: The retinoid X receptor-selective retinoid, LGD1069, downregulates cyclooxygenase- 2 expression in human breast cells through transcription factor crosstalk: implications for molecularbased chemoprevention. Cancer Res 65: 3462-3469, 2005.

22. Orlandi M, Mantovani B, Ammar K, Dal Monte P and Bartolini G: Retinoids and cancer: antitumoral effects of ATRA, 9-cisRA and the new retinoid IIF on the HL-60 leukemic cell line. Med Princ Pract 12: 164-169, 2003.

23. Bartolini G, Orlandi M, Ammar K, Magrini E, Ferreri AM and Rocchi P: Effect of a new derivative of retinoic acid on proliferation and differentiation in human neuroblastoma cells. Anticancer Res 23: 1495-1500, 2003.

24. Bartolini G, Ammar K, Mantovani B, Scannabissi F, Ferreri AM, Rocchi P and Orlandi M: Retinoid and cancer: antitumor effect of ATRA and of a new derivative of retinoic acid, IIF, on colon carcinoma cell lines CaCo-2 and HT-29. Anticancer Res 24: $1779-1783,2004$

25. Bartolini G, Orlandi M, Papi A, Ammar A, Guerra A, Ferreri AM and Rocchi P: Search for multidrug resistance modulators: effects of retinoids in human colon carcinoma cells. In Vivo 20: 729-733, 2006.

26. Pawels R, Balzarini J, Baba M, Snoeck R and Schols D: Rapid and automated tetrazolium-based colorimetric assay for the detection of anti-HIV compounds. J Virol Methods 20: 390-391, 1988 .
27. Casciola-Rosen L, Rosen A, Petri M and Schlissel M: Surface blebs on apoptotic cells are sites of enhanced procoagulant activity: implications for coagulation events and antigenic spread in systemic lupus erythematosus. Proc Natl Acad Sci USA 93: 1624-1629, 1996.

28. Leber TM and Balkwill FR: Zimography: a single-step staining method for quantitation of proteolytic activity on substrate gels. Anal Biochem 249: 24-28, 1997.

29. Lowry DH, Rosebrough NJ, Farr AL and Randall RJ: Protein measurement with the Folin phenol reagent. J Biol Chem 193: 265-275, 1951.

30. Terranova VP, Hic S, Diflorio RM and Lyall RM: Tumor cell metastasis. Crit Rev Oncol Hematol 5: 87-114, 1986.

31. Koopman G, Reutelingsperger CP, Kujten GA, et al: Annexin V for flow cytometric of phosphatidylserine expression on B cells undergoing apoptosis. Blood 84: 1415-1420, 1994.

32. Susin SA, Zanzami M, Castedo T, et al: Bcl-2 inhibits the mitochondrial release of an apoptogenic protease. J Exp Med 184: 1331-1341, 1994.

33. Adams JM and Cory S: The Bcl-2 protein family: arbiters of cell survival. Science 281: 1322-1326, 1998.

34. Reed JC: Bcl-2 family proteins: regulators of apoptosis and chemoresistance in hematologic malignancies. Semin Hematol 34: 9-19, 1997

35. Wild-Bode C: Molecular determinants of glioma cell migration and invasion. FASEB J 13: 781-792, 2001.

36. Wu XZ, Zhang L, Shi BZ and Hu P: Inhibitory effects of N-(4hydrophenyl)retinamide on liver cancer and malignant melanoma cells. World J Gastroenterol 11: 5763-5769, 2005.

37. Golubkov V, Garcia A and Markland FS: Action of fenretinide (4-HPR) on ovarian cancer and endothelial cells. Anticancer Res 25: 249-253, 2005.

38. Yamamoto M, Ueno $\mathrm{Y}$, Hayashi $\mathrm{S}$ and Fukushima T: The role of proteolysis on tumor invasiveness in glioblastoma and metastatic brain tumors. Anticancer Res 22: 4265-4268, 2002.

39. Komatsu K, Nakanishi $Y$, Nemoto N, Hori T, Sawada T and Kobayashi M: Expression and quantitative analysis of matrix metalloproteinase-2 and -9 in human gliomas. Brain Tumor Pathol 21: 105-112, 2004.

40. Murphy G, Knauper V, Lee MH, Amour A, Worley JR, Hutton M, Atkinson S, Rapti M and Williamson R: Role of TIMPs (tissue inhibitors of metalloproteinases) in pericellular proteolysis: the specificity in the detail. Biochem Soc Symp 70: 65-80, 2003.

41. Rao J, Yamamoto M, Mohamans S, et al: Expression and localization of $92 \mathrm{kDa}$ type IV collagenase/MMP9 in human gliomas. Clin Exp Metastasis 14: 8-12,1996.

42. Bode W and Maskos K: Structural basis of the matrix metalloproteinases and their physiological inhibitors, the tissue inhibitors of metalloproteinases. Biol Chem 384: 863-872, 2003

43. Nagase H, Visse R and Murphy G: Structure and function of matrix metalloproteinases and TIMPs. Cardiovasc Res 69: 562-573, 2006.

44. Flannery CR: MMPs and ADAMTs: functional studies. Front Biosci 11: 544-569, 2006.

45. Fisher JF and Mobashery S: Recent advances in MMP inhibitor design. Cancer Metastasis Rev 25: 115-136, 2006.

46. Germanov E, Berman JN and Guernsey DL: Current and future approaches for the therapeutic targeting of metastasis (Review). Int J Mol Med 18: 1025-1036, 2006. 